\title{
The HAC1 gene from Pichia pastoris: characterization and effect of its overexpression on the production of secreted, surface displayed and membrane proteins
}

\author{
Mouna Guerfal1,2, Stefan Ryckaert2,3,5, Pieter P Jacobs²,3,4, Paul Ameloot2,3, Kathleen Van Craenenbroeck6, \\ Riet Derycke 2 and Nico Callewaert*1,2
}

\begin{abstract}
Background: The unfolded protein response (UPR) in eukaryotes upregulates factors that restore ER homeostasis upon protein folding stress and in yeast is activated by a non-conventional splicing of the HAC1 mRNA. The spliced HAC1 mRNA encodes an active transcription factor that binds to UPR-responsive elements in the promoter of UPR target genes. Overexpression of the HACl gene of S. cerevisiae can reportedly lead to increased production of heterologous proteins. To further such studies in the biotechnology favored yeast Pichia pastoris, we cloned and characterized the P. pastoris HAC1 gene and the splice event.

Results: We identified the HAC1 homologue of P. pastoris and its splice sites. Surprisingly, we could not find evidence for the non-spliced HAC1 mRNA when P. pastoris was cultivated in a standard growth medium without any endoplasmic reticulum stress inducers, indicating that the UPR is constitutively active to some extent in this organism. After identification of the sequence encoding active Hac1p we evaluated the effect of its overexpression in Pichia. The KAR2 UPR-responsive gene was strongly upregulated. Electron microscopy revealed an expansion of the intracellular membranes in Hac1 p-overexpressing strains. We then evaluated the effect of inducible and constitutive UPR induction on the production of secreted, surface displayed and membrane proteins. Wherever Hac1 p overexpression affected heterologous protein expression levels, this effect was always stronger when Hac1 p expression was inducible rather than constitutive. Depending on the heterologous protein, co-expression of Hac1 p increased, decreased or had no effect on expression level. Moreover, a-mating factor prepro signal processing of a G-protein coupled receptor was more efficient with Hac1 p overexpression; resulting in a significantly improved homogeneity.
\end{abstract}

Conclusions: Overexpression of P. pastoris Hac1 p can be used to increase the production of heterologous proteins but needs to be evaluated on a case by case basis. Inducible Hac1 1 expression is more effective than constitutive expression. Correct processing and thus homogeneity of proteins that are difficult to express, such as GPCRs, can be increased by co-expression with Hac1p.

\section{Background}

Secreted proteins enter the secretory pathway in the endoplasmic reticulum (ER), where they undergo co- and posttranslational modifications, such as glycosylation, phosphorylation, and the formation of disulfide bridges. Only correctly folded proteins leave the ER and proceed

* Correspondence: Nico.Callewaert@dmbr.vib-Ugent.be

1 Department of Biochemistry and Microbiology, Ghent University, Ghent, Belgium

Full list of author information is available at the end of the article through the exocytic pathway. Accumulation of unfolded and misfolded proteins in the ER triggers the activation of the unfolded protein response (UPR). According to current models, the UPR in S. cerevisiae is a linear signaling pathway regulating the transcription of UPR target genes encoding chaperones, foldases, and proteins involved in glycosylation, lipid metabolism, etc.[1,2] (Fig. 1). The most prominent components regulating the UPR are the kinase/RNase, Ire1p and the transcription factor Hac1p. 


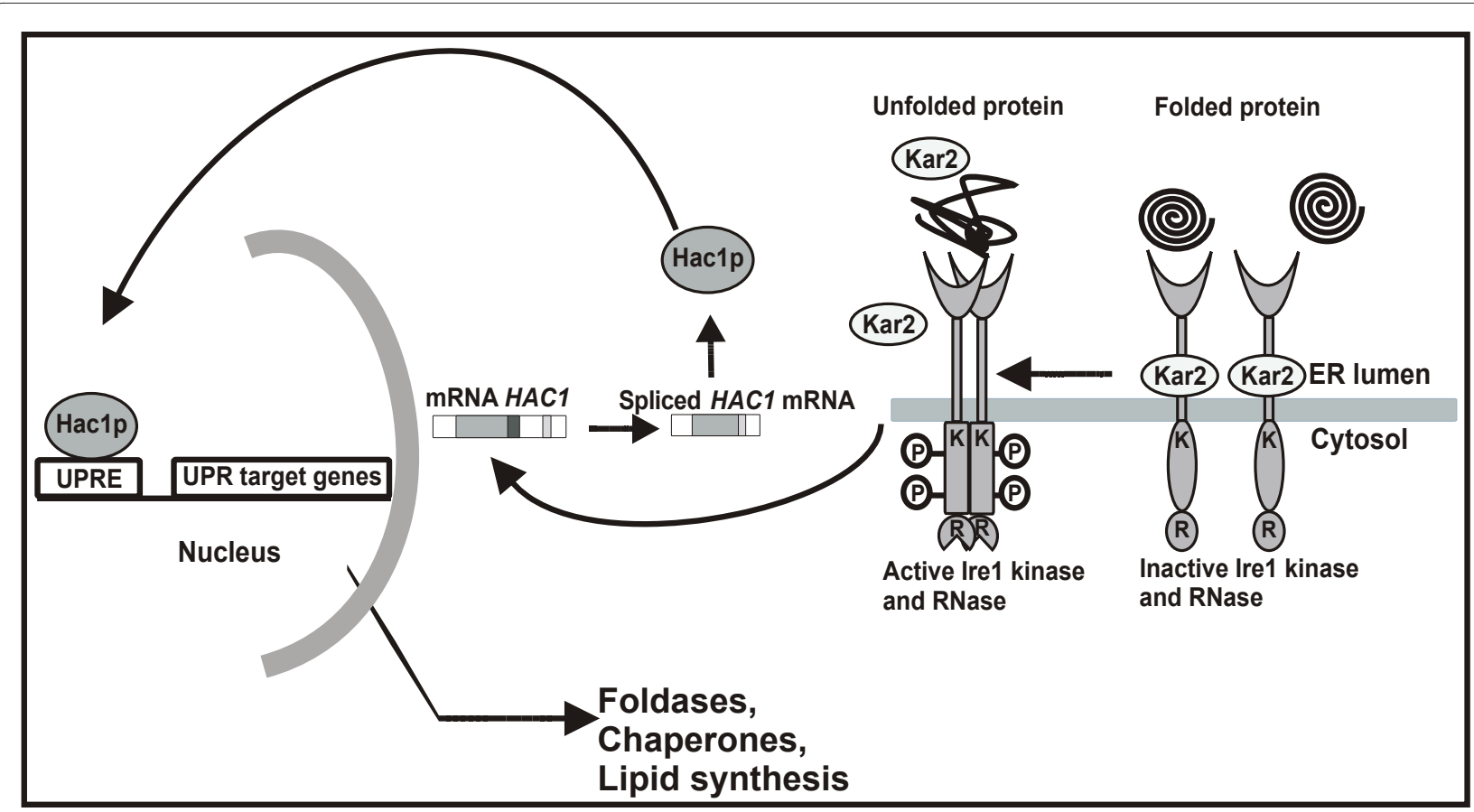

Figure 1 The unfolded protein response in the yeast S. cerevisiae. Under normal conditions Ire $1 \mathrm{p}$ is present in the ER membrane as a monomer in association with Kar2/Bip. Upon ER stress, in a first step, Kar2 dissociates from Ire1 p which causes clustering of Ire $1 \mathrm{p}$ in the ER membrane. In a second step, direct interaction of the unfolded protein with a stress sensing region of the Ire $1 \mathrm{p}$ orients the cytosolic effector domains [4]. Clustering causes transautophosphorylation of the kinase domain $(K)$ and simultaneous activation of the endoribonuclease $(R)$ activity. Activation of Ire $1 p$ initiates an unconventional mRNA splicing reaction, which removes an intron from a unique mRNA species, HACl, which encodes for an active transcription factor. Hac1p activates target genes coding for chaperones, foldases, lipid synthesis etc.

Under non-stress conditions Ire1p is a monomeric protein closely associated with the ER chaperone Bip/Kar2p [3]. As unfolded proteins accumulate in the ER lumen, $\mathrm{Bip} / \mathrm{Kar} 2 \mathrm{p}$ is released from Ire1p, which allows it to cluster and to interact with the unfolded proteins [4]. Clustering induces autophosphorylation of Ire1p and activates its RNase function. Activation of Ire1p initiates an unconventional splicing reaction of the $H A C 1$ mRNA, at two specific sites different from the consensus intron sites recognized by the spliceosome.

HAC1 mRNA is constitutively expressed, but due to the secondary structure of the intron, no protein is produced when the mRNA remains unspliced [5]. Removal of the intron releases the translational block in the HAC1 mRNA. Finally, Hac1p is translocated to the nucleus, where it binds to UPR responsive elements (UPRE) in the promoter of UPR target genes. HAC1 homologues have been identified in mammals $(X B P 1)$, C. elegans $(X B P 1)$ and filamentous fungi $(H A C 1 / H A C A)$, and they undergo similar splicing reactions [6-8].

The methylotrophic yeast, $P$. pastoris, is widely used to express heterologous proteins. Different approaches are used to manipulate $P$. pastoris in order to increase the production of secreted proteins. As the UPR expands the ER's capacity of protein folding, attempts have been made to exploit this signal transduction pathway to augment recombinant protein expression. Several groups have described the effect of the constitutive expression of functional Haclp from S. cerevisiae on the production of secreted heterologous proteins $[9,10]$. However, no study has reported the use of a $P$. pastoris Haclp homolog because until now no HAC1 gene had been identified in this methylotrophic yeast. The aim of this study was to isolate the $H A C 1$ gene from Pichia pastoris and to identify the intron that is spliced out to obtain functional Hac1p. After identifying the active Haclp, we evaluated the effect of its overexpression in Pichia on the expression level of the UPR target gene Kar2p, on the morphology of intracellular membranes, and on growth of the yeast. We also evaluated the effect of Hac1p overexpression on the expression levels of surface displayed, secreted and membrane-bound heterologous proteins.

\section{Results and Discussion}

\section{Identification of the $H A C 1$ gene and its splice sites}

The unconventional splicing of the HAC1 mRNA mediated by the transmembrane protein Ire1p plays a major role in activation of the UPR. Functional HAC1 homologues have been identified in C. elegans, mammals and filamentous fungi [6-8]. The sequence of the $H A C 1$ gene 
from $P$. pastoris was found when searching for homologies to the $H A C 1$ gene of $S$. cerevisiae in a draft of the $P$. pastoris genome (search kindly performed by James Cregg). A hit was found based on the homology between the relatively conserved DNA binding basic leucine zipper (bZIP) domains. Alignment of the AA sequence of Pichia Haclp and other Haclp homologues from yeast and filamentous fungi shows that there is no pronounced homology between the sequences, except in the bZIP domain (Fig. 2).

Recently it was shown that a bipartite sequence in the $3^{\prime}$ UTR of the HAC1 mRNA from S. cerevisae targets the unspliced mRNA to Ire1p for splicing [11,12]. The HAC1 3'UTR contains an extended stem-loop structure and two short sequences within this stem-loop are highly conserved in different HAC1 orthologues. A similar stem- loop structure was identified in the Pichia HAC1 3' untranslated region (Fig. 3A). As expected, conserved sequence motifs are juxtaposed in the distal part of the stem.

As the region around the splice sites of the $H A C 1$ gene is relatively conserved, we were able to identify potential splice sites in the P. pastoris HAC1 gene by sequence similarity between the intronic regions of the P. pastoris and S. cerevisiae HAC1 genes (Fig. 3B). We predicted the splice sites to reside in characteristic stem-loop structures consisting of two seven-base rings resembling those found in S. cerevisiae HAC1 and H. sapiens XBP1 (Fig. 3D) $[13,7]$. We found that the intron consisted of 322 base pairs. The 5 ' splice site is situated in the coding region of the $H A C 1$ gene, and splicing leads to replacement of the sequence encoding the $\mathrm{C}$-terminal $45 \mathrm{AA}$ by a sequence

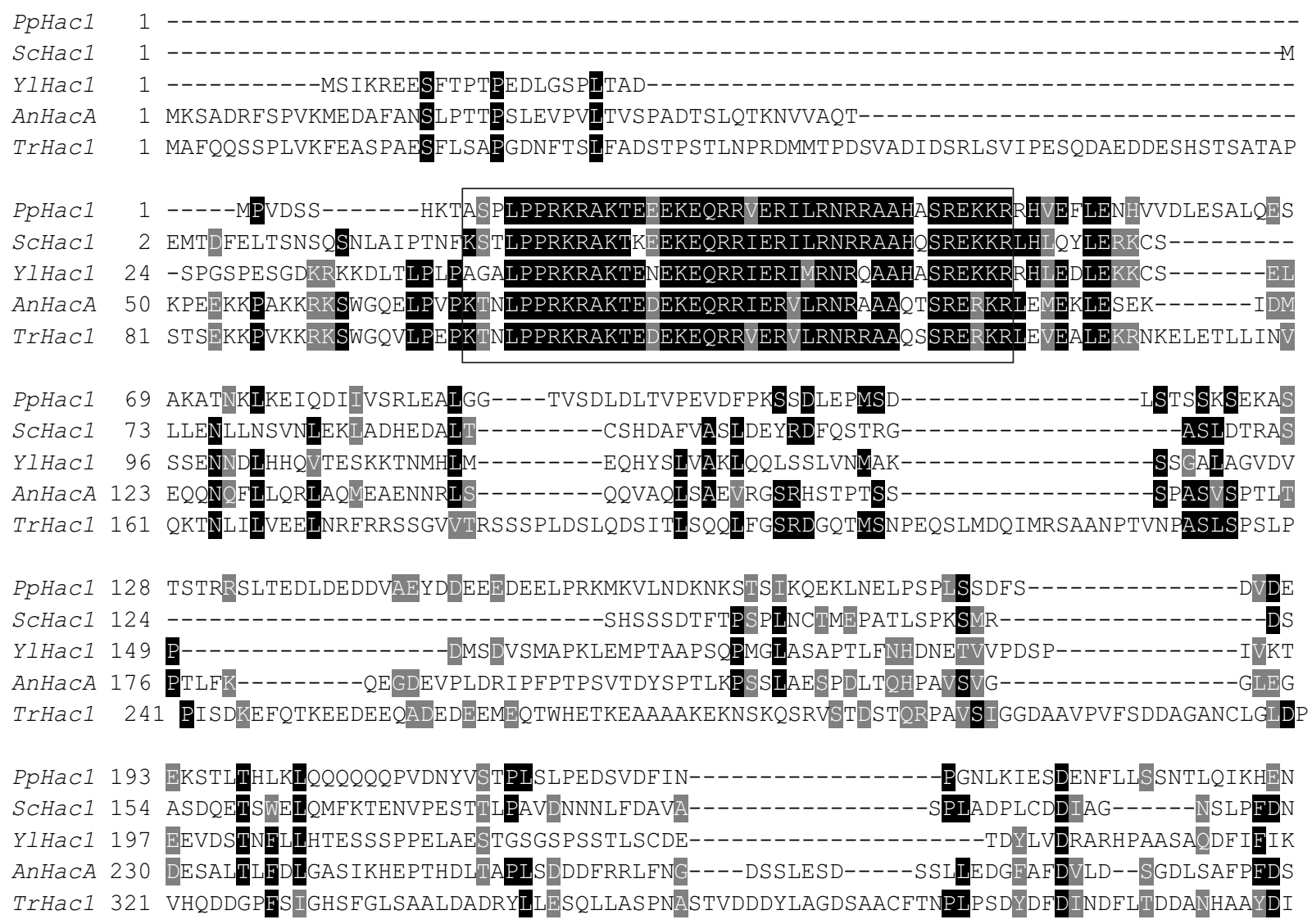

Figure 2 Multiple sequence alignment of different Hac1p homologues. Alignment of the amino acid sequence of Hac1 p of P. pastoris (Pp), S. cerevisiae (SC), Y. lipolytica (YI), A. nidulans (An) and T. reesei (Tr). Only in the DNA binding bZIP domain similarity is observed (boxed). 


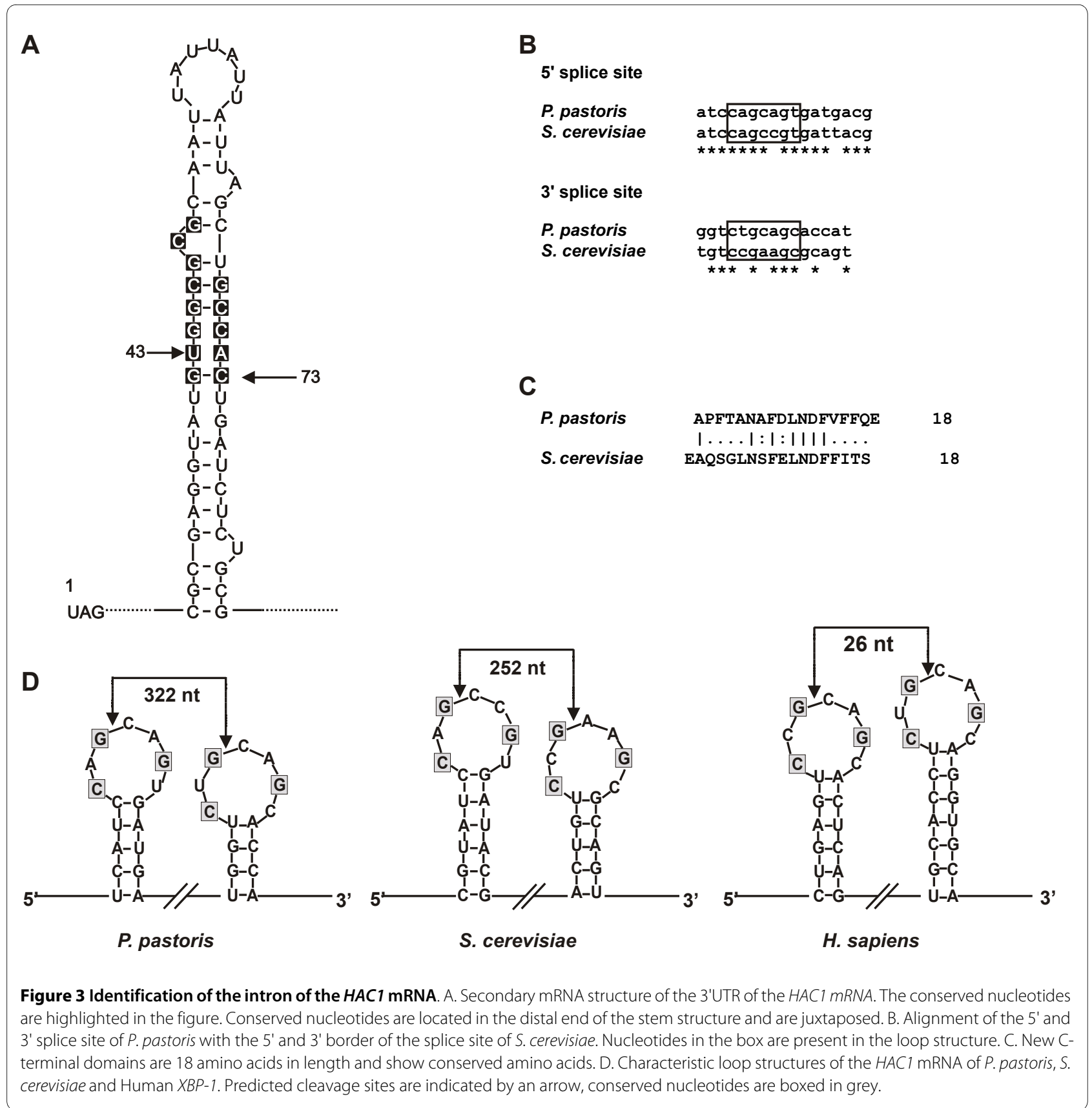

encoding 18 AA somewhat similar to the C-terminal part of the S. cerevisiae Hac1p (Fig. 3C).

The presence of an IRE1 homolog (XP_002493349) in the Pichia genome and the characteristics described above support an Ire1p mediated splicing reaction. Unspliced HAC1 mRNA is targeted to the Ire1p clusters via the bipartite region identified in the 3'UTR of the mRNA and splicing takes place at the identified stemloop structures. The spliced $H A C 1 \mathrm{mRNA}$ is translated to an active transcription factor which binds to UPRE (unfolded protein responsive elements) in UPR target genes. The best characterized UPRE, UPRE-1 (CAN-
CNTG), is found in the promoter of the Pichia HAC1 gene (CAACTTG) and previously identified UPR target genes [14] such as KAR2 (CAGCGTG) and INO1(CAACTTG). The presence of an UPRE in the promoter of the $H A C 1$ gene shows that Hac1p can up-regulate its own transcription as is also seen in S. cerevisiae [15].

\section{Confirmation of the splice sites}

To confirm the predicted splice sites, UPR was induced by adding dithiothreitol (DTT) to a Pichia culture in the mid-exponential growth phase. DTT disrupts the forma- 
tion of disulfide bridges during folding in the ER, which results in accumulation of unfolded proteins. First strand cDNA was generated based on RNA fractions isolated from cultures in which UPR was either induced or not induced. An amplification product of the size expected for the spliced HAC1 mRNA was obtained for both the induced and the non-induced conditions (Fig. 4).

As this result shows that $H A C 1$ mRNA splicing is constitutive in $P$. pastoris, it may indicate continuous folding stress on the growth temperature of $30^{\circ} \mathrm{C}$ used here. Therefore we also checked whether decreasing the growth temperature to $20^{\circ} \mathrm{C}$ alters the observed constitutive $H A C 1$ mRNA splicing but no unspliced $H A C 1$ mRNA was detected also at $20^{\circ} \mathrm{C}$ (Fig. 4). The amount of spliced HAC1 mRNA is however upregulated under stress conditions, indicating that ER stress regulates the transcription of HAC1 mRNA. The RT-PCR product was sequenced and its alignment with the P. pastoris $H A C 1$ locus fully confirmed the predicted splice sites. We speculate that a basal splicing activity of the HAC1 mRNA

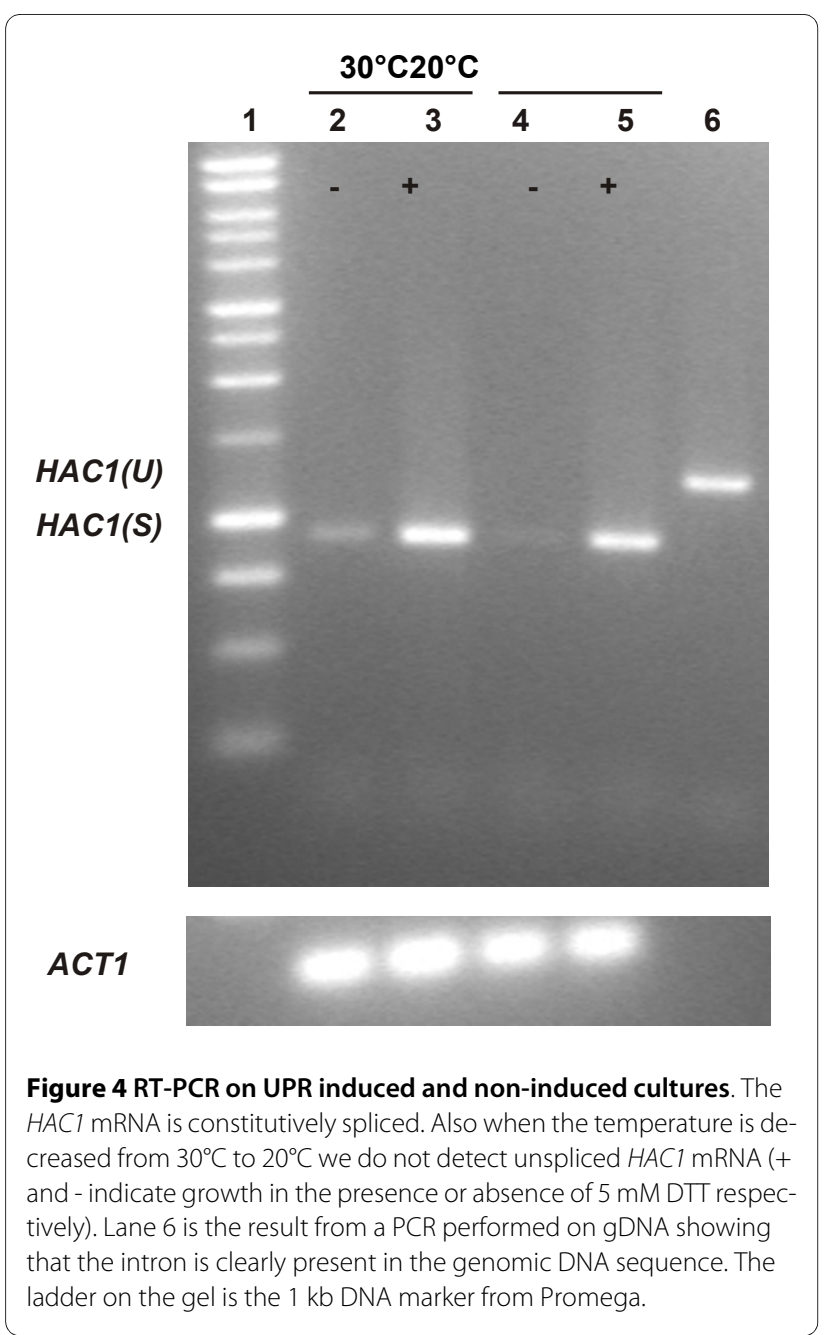

and consequently a basal UPR activity might be one of the reasons why Pichia is a proficient protein secretor.

\section{Cloning and overexpression of the spliced $H A C 1$ gene (HAC(S))}

To acquire the complete open reading frame of $P$. pastoris $H A C 1(S)$, RT-PCR was performed on total RNA from a UPR induced culture. The cDNA fragment was cloned under control of the AOX1 promoter in the expression vector pBLHISIX. The resulting plasmid, pAOXHAC1, was transformed to $P$. pastoris GS115 cells and targeted into the HIS4 locus.

After induction of $H A C 1(S)$ expression with methanol, transcriptional activation of the UPR was analyzed by quantifying KAR2 mRNA levels by qPCR. KAR2 is the best characterized UPR target gene. The expression level was nine-fold higher than in cells transformed with the empty vector, pBLHISIX (Fig. 5A). Besides observing upregulation of KAR2 mRNA, we also observed increased amounts of Kar2p and Pdip (identity confirmed by mass spectrometry, data not shown), which normally reside in the ER, in the culture supernatants of strains expressing $H A C 1(\mathrm{~S})$ (Fig. 5C). This confirms reported findings: treatment with chemical agents that interfere with protein folding leads to secretion of Kar2p and other HDEL-containing proteins [16]. Kar2p is also secreted when cells overexpress heterologous proteins that induce UPR stress [17]. Secretion of HDEL-containing ER proteins could be a general characteristic of the UPR. It is possible that the maximum capacity of the ER retrieval mechanism is exceeded upon ER stress and proteins cannot be successfully retained anymore in the ER.

In contrast to previous reports, which showed that constitutive expression of active Hac1p slows the growth of $S$. cerevisiae $[18,19]$, we did not observe a growth defect consequent to inducible expression of $P$. pastoris $H A C 1(S)$ (Fig. 5B).

The ER is the major site of lipid synthesis in the cell and can expand when considerable strain is placed on the secretory pathway. When unfolded and misfolded proteins accumulate in the ER, the ER needs to expand to accommodate them. This is reflected by increased biosynthesis of phosphatidyl-inositol and other lipids after UPR activation [20-23]. We investigated changes in intracellular membrane morphology by electron microscopy (EM) of P. pastoris cells overexpressing HAC1(S). Cells were grown on methanol-containing medium for $48 \mathrm{~h}$ before being fixed for EM. In P. pastoris, we observed discrete regions of stacked membranes of seven or more well organized layers upon expression of $H A C 1(S)$ (Fig. 5D). The organization of the membranes differs from the membrane sheets observed in $S$. cerevisiae upon UPR induction. The membranes have a primitive cubic membrane morphology and it is the first time this membrane 


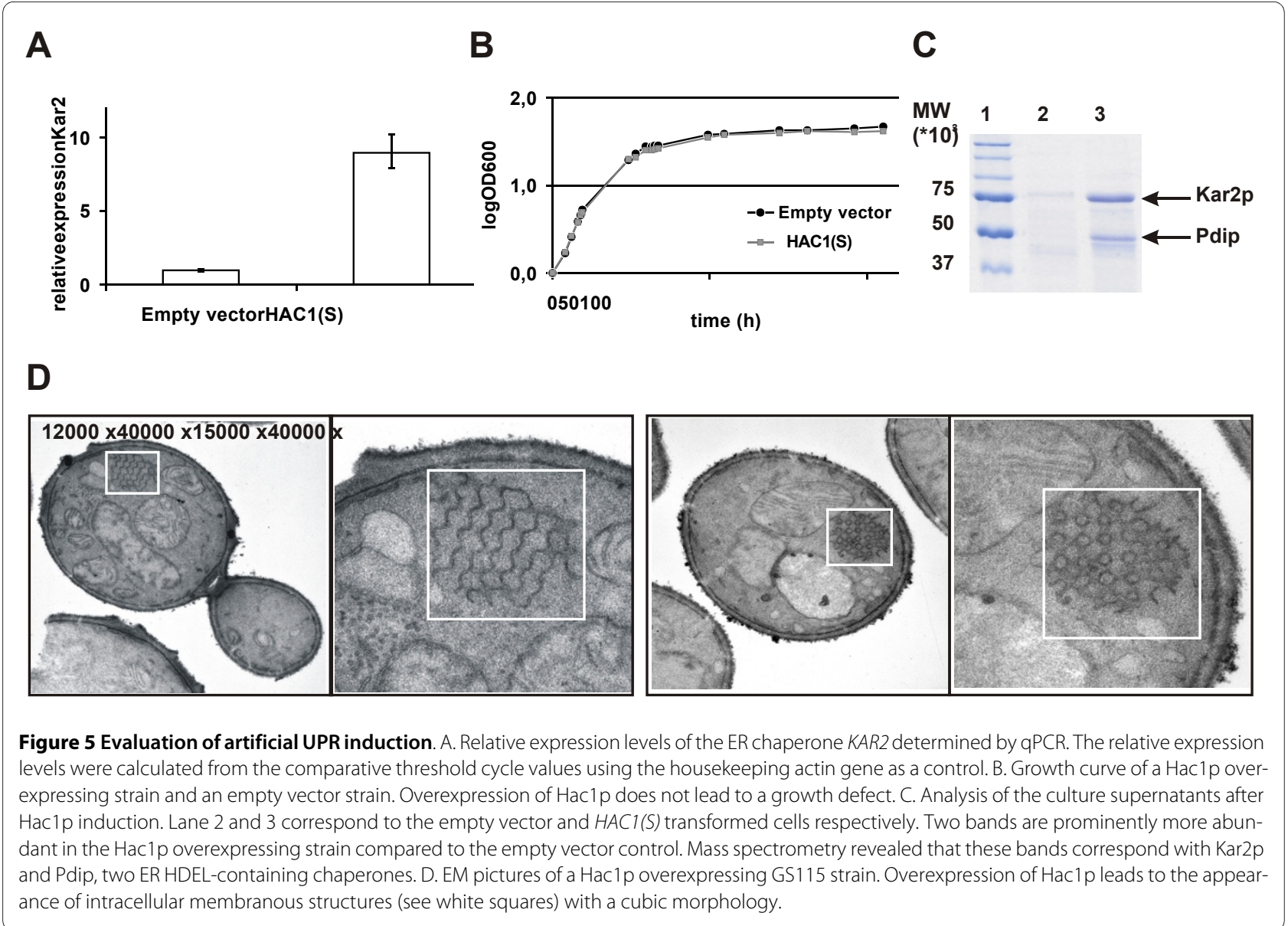

organization is observed in yeast. The fact that yeast can induce cubic membranes can be of great interest for the analysis of the biogenesis of such membranes.

\section{Expression of heterologous proteins}

The production of large amounts of recombinant proteins is required for several pharmaceutical, biomedical and biotechnological applications, and so it is important to develop and optimize techniques to increase the yield of the proteins of interest. Overexpression of molecular chaperones is frequently employed to achieve this goal. As Hac1p overexpression leads to increased expression of the chaperones Bip/Kar2p, Pdip and others, co-expression of Hac1p has been explored as a means to increase expression of heterologous proteins. Constitutive expression of functional $S$. cerevisiae Hac1p leads to increased secretion of some homologous and heterologous proteins in S. cerevisiae [24,25], P. pastoris [9] and filamentous fungi [24]. We expressed homologous Pichia Hac1p in combination with heterologous proteins and evaluated the inducible expression of the transcription factor.

\section{Surface displayed proteins}

To compare the effect of induced and constitutive overexpression of Hac1p on the expression of heterologous pro- teins, we used yeast surface display [26,27]. In this procedure, the protein of interest is fused to an endogenous yeast protein that is transported through the secretory pathway and which mediates covalent incorporation in the yeast cell wall. It has been demonstrated that the surface display level of a series of mutant single chain $\mathrm{T}$ cell receptors (scTCR) correlated well with soluble secretion levels, which suggests that the yeast surface display level could be used as readout for secretion efficiency [28]. Thus, we quantified the surface display levels of four heterologous proteins (mouse interferon- $\gamma$, human interferon- $\beta$, human thrombomodulin and human erythropoietin) in the presence or absence of HAC1p (expressed inducibly from the AOX1 promoter or constitutively from the GAP promoter) (Fig. 6A).

For the strains expressing the Hac1p protein constitutively, there was little or no improvement in surface expression levels compared to reference strains expressing the surface protein alone (Fig. 6A). For the strains overexpressing the inducible Hac1p, the expression level was either lower or higher, as follows: a) in the strain displaying mouse interferon- $\gamma$, the expression level was 1.8fold lower; b) in the strain displaying human interferon- $\beta$, the low initial expression level was completely abolished; 


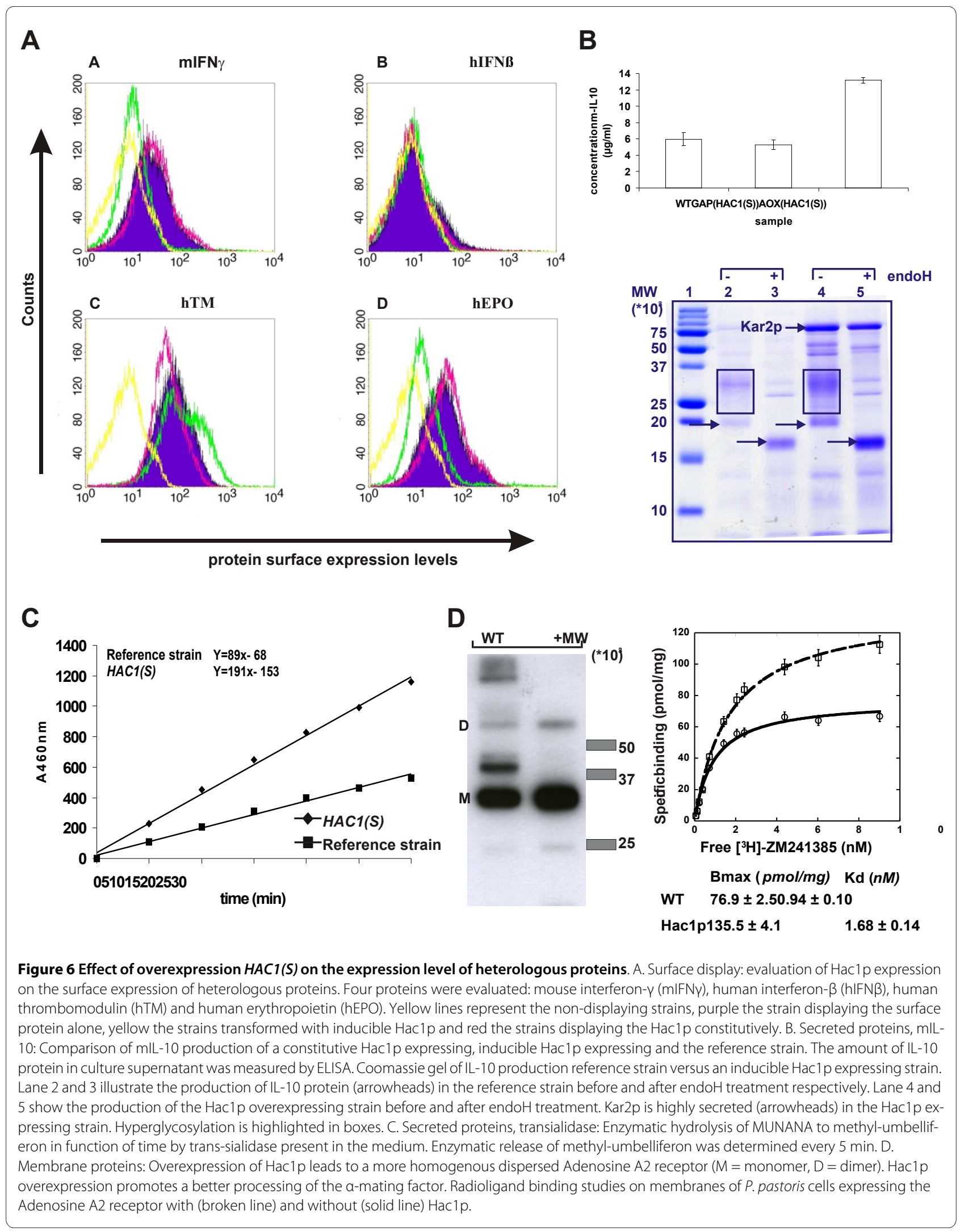


c) in the strain displaying human thrombomodulin, the expression level increased 1.9-fold compared to the reference strain, and d) in the strain displaying human erythropoietin, expression was 1.3-fold lower.

\section{Secreted proteins}

The spliced $H A C 1 \mathrm{cDNA}$ under the control of the methanol-inducible AOX1 promoter was transformed to strains expressing mIL-10 or Trypanosoma cruzi trans-sialidase (TS) protein under control of the AOX1 promoter.

The expression of the mIL-10 protein in the absence or presence of constitutive or inducible expressed Haclp was evaluated by ELISA. Results showed that comparable expression levels were obtained for the mIL-10 strain expressing the Hac1p constitutively (Fig. 6B). Co-expression of inducible Hac1p improved mIL-10 protein yield up to 2.2 times (Fig. 6B). Significant Kar2p secretion was observed in the strain expressing inducible $H A C 1(S)$ (Fig. 6B).

Secretion of trans-sialidase was assessed by measuring the enzymatic hydrolysis of 4-methyl-umbelliferyl-Nacetylneuraminic acid (MUNANA). TS strains expressing inducible HAC1p secreted up to 2.1-fold more TS than the reference strain (Fig. 6C). Coomassie stained gels showed that co-expression of Haclp also here led to substantial secretion of Kar2p (data not shown).

\section{Membrane proteins}

To evaluate the effect of Hac1p overexpression on the expression of heterologous membrane proteins, we used the G-protein coupled receptor, Adenosine A2A receptor as a model. Expression of the receptor was analyzed by western blot, detecting the Rho1D4-tag present on the receptor. For the strains not overexpressing $H A C 1(S)$, a prominent band appears of which the molecular weight corresponds to the monomeric receptor, accompanied with bands at higher molecular weight, probably corresponding to oligomers (Fig. 6D). Moreover a strong about $10 \mathrm{kDa}$ higher band then the monomer is observed which is likely due to an incompletely processing of the pro-peptide in the $\alpha$-mating factor leader sequence $(9.3 \mathrm{kDa})$ which was used. Incomplete processing of the mating factor has been reported for other receptors expressed in $P$. pastoris [29]. However, very interestingly this higher molecular weight band is not present when the receptor is co-expressed with Hac1p, concomitant with an increased abundance of the band at the expected molecular weight of the monomer. It seems that co-expression of the A2A receptor with Hac1p leads to a more homogeneously dispersed receptor.

To test whether the adenosine A2A receptor is properly folded, radioligand binding studies on total membrane preparations were performed. These studies showed that the receptor fraction in the Hac1p-overexpressing strain can bind more ligand than the wild type strain (135.5 \pm $4.1 \mathrm{pmol} / \mathrm{mg}$ versus $76.9 \pm 2.5 \mathrm{pmol} / \mathrm{mg}$; Fig. $6 \mathrm{D}$ ), a $1.8 \%$ increase is obtained, whereas its ligand affinity was reduced somewhat.

Seen the results of co-expression of Hac1p with heterologous proteins, we show that constitutive expression of functional Hac1p had only minor effects on the expression levels of proteins, if any at all. By contrast, inducible expression of Haclp either increased or decreased the yield, depending on the protein evaluated.

Inducible expression of Haclp might have reduced the expression of some proteins because different proteins may benefit from different levels of UPR induction, and in these instances the AOX1 promoter might have induced the UPR at an unsuitably high level. Moreover, UPR also activates the ER-associated degradation pathway (ERAD), which implies that if a protein's folding is not improved by the co-expression of chaperones, it will be targeted to the protein degradation pathway. This might also explain the observed decrease in the level of some proteins. The study of $H A C 1(S)$ under control of different promoters can be useful for optimizing chaperone co-expression.

We show that co-expression of Haclp can be extremely useful when overexpressing membrane proteins for crystallography. A better processing of the $\alpha$-mating factor is seen for the A2A receptor when coexpressed with Hac1p. This leads to a more homogenous receptor preparation which will facilitate crystal growth.

\section{Conclusion}

From our studies we conclude that overexpression of Hac1p can be used as a technique to increase the production and the correct leader sequence processing of heterologous proteins but needs to be evaluated on a case by case basis. To express a single protein in heterologous hosts one has to overrule its specific bottleneck. Coexpression of chaperones to increase production levels is a trial and error process, but with substantial payoffs when successful. We also show that for GPCR's that are difficult to express, co-expression with Hac1p does not necessarily increase the amount of receptor but it can result in a more homogenously dispersed receptor which will facilitate crystallization for this class of proteins.

\section{Materials and methods Strains}

MC1061 cells were used for the amplification of recombinant plasmid DNA. The P. pastoris strain GS115 (his4) was used to identify the $H A C 1$ intron and to analyze the effect of overexpression of $H A C 1(S)$ on the cells. For the yeast surface display experiments, we used GlycoswitchMan5 strains [30] expressing fusion proteins under control of the inducible AOX1 promoter: human interferon- $\beta$ with a-agglutinin; mature mouse interferon gamma with a-agglutinin; mature human erythropoietin 
with a-agglutinin; the lectin-like domain of mouse thrombomodulin with a-agglutinin. To evaluate the effect of the $H A C 1(S)$ co-expression on production of mouse IL-10 and trans-sialidase, we used a $P$. pastoris GS115 strain expressing mouse IL-10 and a $P$. pastoris GlycoSwitchMan5 strain expressing trans-sialidase, both under control of the AOX1 promoter. A P. pastoris GS115 strain expressing the A2A receptor provided with a Rho1D4-Tag under control of the AOX1 promoter was used to evaluate the effect of $H A C 1(S)$ on membrane protein expression.

\section{Media}

Depending on the experimental settings, yeast strains were grown in YPD medium $(10 \mathrm{~g} / \mathrm{L}$ yeast extract, $20 \mathrm{~g} / \mathrm{L}$ peptone, $20 \mathrm{~g} / \mathrm{L}$ dextrose), BMGY (buffered Glycerolcomplex Medium: $100 \mathrm{mM}$ potassium phosphate $\mathrm{pH} 6.0$ containing check $13.4 \mathrm{~g} / \mathrm{L}$ YNB without amino acids, 10 $\mathrm{g} / \mathrm{l}$ yeast extract, $20 \mathrm{~g} / \mathrm{L}$ peptone and $10 \mathrm{~g} / \mathrm{L}$ glycerol) or BMMY (Buffered Methanol-complex Medium: $100 \mathrm{mM}$ potassium phosphate $\mathrm{pH} 6.0$ containing $13.4 \mathrm{~g} / \mathrm{L} \mathrm{YNB}$ without amino acids, $10 \mathrm{~g} / \mathrm{L}$ yeast extract, $20 \mathrm{~g} / \mathrm{L}$ peptone and $10 \mathrm{~g} / \mathrm{L}$ methanol). BMY was used as washing medium (100 mM potassium phosphate $\mathrm{pH} 6.0$ containing $13.4 \mathrm{~g} /$ $\mathrm{L}$ YNB without amino acids, $10 \mathrm{~g} / \mathrm{L}$ yeast extract and 20 $\mathrm{g} / \mathrm{L}$ peptone).

\section{Plasmid construction}

The intronless $H A C 1$ cDNA was isolated from an UPR induced culture using forward primer 5'-GAATTCATGCCCGTAGATTCTTCTC-3' and reverse primer 5'GCGGCCGCCTATTCCTGGAAGAATACAAAGTC-3', introducing an EcoRI site and a NotI site, respectively. The resulting PCR fragment was digested EcoRI and NotI and cloned behind the AOX1 or GAP promoter of the EcoRI/NotI opened plasmids pBLHISIX (J. Cregg) and pBLHISIX/GAP, respectively. The resulting plasmids were named pAOXHAC1 and pGAPHAC1.

\section{Strain construction}

Competent P. pastoris cells were prepared and transformed by electroporation according to the protocol from the Pichia Expression kit (Invitrogen Cat. No. K1710-01). The pAOXHAC1 vector was linearized in the HIS4 gene to target the construct to the HIS4 locus for integration. Transformants were plated on RDB-HIS4 agar plates. Genomic DNA was prepared using the Epicenter Kit (Epicenter Biotechnologies, Madison, WI) and genomic integration was confirmed by PCR.

\section{UPR induction and identification of the splice site}

Exponential phase cultures were incubated at $20^{\circ} \mathrm{C}$ or $30^{\circ} \mathrm{C}$ in the absence or the presence of $5 \mathrm{mM}$ DTT for $1 \mathrm{~h}$. RNA was isolated, treated with DNAse, and reverse transcribed using the iScript ${ }^{\text {tw }} \mathrm{cDNA}$ Synthesis kit from BioRad. Two microliters of cDNA was used in a PCR reac- tion with forward primer 5'-GAA TTC ATG CCC GTA GAT TCT TCT C-3' and reverse primer 5'-GCG GCC GCC TAT TCC TGG AAG AAT ACA AAG TC-3' (2 min $95^{\circ} \mathrm{C}, 30 \sec 95^{\circ} \mathrm{C}, 30 \sec 50^{\circ} \mathrm{C}, 1 \min 30 \sec 72^{\circ} \mathrm{C} ; 40$ cycles).

\section{Isolation of total RNA}

Cells harvested in the exponential growth phase were washed once with sterile DEPC-treated water, and then 1 ml RNApure Reagent (Genhunter Corporation, Nashville, TN) and $1 \mathrm{~g}$ of baked glass beads were added. Cells were broken by vortexing $2 \times 2$ min using a Mixer Mill. The lysate was combined with $150 \mu \mathrm{l}$ of chloroform, vortexed for $10 \mathrm{~min}$, and centrifuged for $20 \mathrm{~min}$ at 13,000 $\mathrm{rpm}$ at $4^{\circ} \mathrm{C}$. The upper phase was collected in a new tube and the RNA was precipitated with isopropanol on ice for $10 \mathrm{~min}$. RNA was pelleted by centrifugation for $10 \mathrm{~min}$ at $13,000 \mathrm{rpm}$ and $4{ }^{\circ} \mathrm{C}$ and washed with $70 \%$ of ice-cold ethanol. The RNA was resuspended in $50 \mu$ l RNAse free water.

\section{Quantitative PCR}

After DNase I digestion (RNase-free DNase Set Qiagen), $100 \mathrm{ng}$ of RNA was reversed transcribed using the iScript ${ }^{\text {mat }}$ CDNA Synthesis kit from Bio-Rad. Template cDNA (corresponding to $25 \mathrm{ng}$ RNA) was amplified in 25 $\mu \mathrm{l}$ containing $150 \mathrm{nM}$ of the respective primers and 12.5 $\mu \mathrm{l}$ SYBR Green reaction buffer (Eurogentec). The absence of DNA contamination in RNA samples was tested by including RNA samples that had not been reverse transcribed. PCR conditions were as followed: $2 \mathrm{~min}$ at $50^{\circ} \mathrm{C}$, $10 \mathrm{~min}$ at $95^{\circ} \mathrm{C}$, followed by 40 cycles of $15 \mathrm{sec}$ at $95^{\circ} \mathrm{C}, 20$ sec at $60^{\circ} \mathrm{C}$ and $40 \mathrm{sec}$ at $72^{\circ} \mathrm{C}$. A melting curve was done to ensure that only a specific amplification product was obtained. Primer sequences were designed by Primer Express software (Applied Biosystems): Actin: 5'-GGTATTGCTGAGCGTATGCAAA-3' (forward) and 5'CCACCGATCCATACGGAGTACT-3' (reverse); Bip/ Kar2: 5'-CCAGCCAACTGTGTTGATTCAA-3' (forward) and 5'-GGAGCTGGTGGAATACCAGTCA-3' (reverse). The relative amounts of mRNA were calculated from the comparative threshold cycle values using the actin gene as a control.

\section{Growth curve}

An overnight preculture in $\mathrm{BMGY}$ at $30^{\circ} \mathrm{C}$ was diluted in $\mathrm{BMMY}$ to an $\mathrm{OD}_{600}$ of 1 and incubation was continued. $\mathrm{OD}_{600}$ was measured at different times and $\log \mathrm{OD}_{600}$ was plotted against time.

\section{Shake flask cultures $(H A C 1(S)$ induction and heterologous protein induction)}

A pre-inoculum starting from a single colony was grown overnight in $5 \mathrm{ml}$ of $\mathrm{BMGY}$ at $30^{\circ} \mathrm{C}$ and $220 \mathrm{rpm} . \mathrm{OD}_{600}$ was measured in the morning and the cells were diluted 
to an $\mathrm{OD}_{600}$ of 1 in a total of $12.5 \mathrm{ml}$ BMGY in a $125 \mathrm{ml}$ shake flask and grown for another $48 \mathrm{~h}$. Cells were washed once with BMY, resuspended in BMMY, and induced for $48 \mathrm{~h}$. Methanol (100\%) was added every 8-12 $\mathrm{h}$ to a final concentration of $1 \%$ to maintain the induction. The adenosine A2A receptor was induced for $24 \mathrm{~h}$ before harvesting for analysis.

\section{mIL-10 ELISA}

The amount of mouse IL-10 protein in the culture supernatants was measured by ELISA using Mouse IL-10 Cytoset (BIOSOURCE). Culture supernatants were diluted 1/ $4000,1 / 8000,1 / 12000$ and 1/16000. Absorbance was measured at $450 \mathrm{~nm}$ with a reference absorbance of 650 nm (Thermo labsystems, Multiskan EX).

\section{Trans-sialidase assay}

Trans-sialidase activity in the medium was measured by measuring the initial velocity of the hydrolysis of 4methyl-umbelliferyl-N-acetylneuraminic acid (MUNANA) to fluorescent methyl-umbelliferon in a cytofluorometer (excitation and emission wavelengths at $360 \mathrm{~nm}$ and $460 \mathrm{~nm}$, respectively). Twenty microliters of medium was added to $100 \mu \mathrm{PBS}$ containing $0.1 \%$ BSA and $500 \mu \mathrm{M}$ MUNANA. Enzymatic release of methylumbelliferon was determined every $5 \mathrm{~min}$. When fluorescence values are plotted as a function of time, the slopes of the linear curves allow comparison of the trans-sialidase activities in the media.

\section{Protein analysis}

Mouse IL-10

$\mathrm{OD}_{600}$ was measured after induction. Proteins in supernatant corresponding to $2.8 \times 10^{7}$ cells were precipitated with DOC/TCA and separated in a 15\% SDS-PAGE gel. Proteins were visualized by staining with Coomassie Brilliant Blue.

\section{Adenosine $\mathrm{A} 2 \mathrm{~A}$ receptor}

After induction, cells were centrifuged at $1500 \times \mathrm{g}$ and the pellet was resuspended in ice-cold breaking buffer (50 $\mathrm{mM}$ sodium phosphate buffer $\mathrm{pH} 7.4$, complete protease inhibitor (Roche), 5\% glycerol). Cells were broken by vigorous vortexing with glass beads in a mixer mill for $10 \times 1$ min at $4^{\circ} \mathrm{C}$. Cells were separated from the membrane suspension by low speed centrifugation $(1000 \times \mathrm{g}, 20 \mathrm{~min}$, $\left.4^{\circ} \mathrm{C}\right)$. Membranes were pelleted at $100,000 \times \mathrm{g}$ and $4^{\circ} \mathrm{C}$ for $60 \mathrm{~min}$ and resuspended in resuspension buffer $(50 \mathrm{mM}$ sodium phosphate buffer $\mathrm{pH} 7.4$ supplemented with a complete protease inhibitor from Roche) and snap-frozen in liquid nitrogen. The protein concentration of the membrane preparation was determined using the BCA reagent (Pierce, Rockford, IL) with BSA as a standard. Five micrograms of total membrane protein was analyzed by western blot. The blot was blocked overnight in block- ing buffer $(0.05 \%$ Tween-20 and $3 \%$ casein in $1 \times$ PBS) and probed with a $1 / 500$ diluted primary mouse anti-Rho1D4 antibody, followed by a $1 / 3000$ diluted secondary antimouse IgG peroxidase from sheep (Sigma Cat.n ${ }^{\circ}$ NA931V). Protein bands were visualized with Renaissance western blot chemiluminescence reagent plus (PerkinElmer).

\section{Ligand binding studies $\mathrm{A} 2 \mathrm{~A}$ receptor}

The procedures for studying binding at recombinant $\mathrm{A} 2 \mathrm{~A}$ receptors have been described [31]. Briefly, $5 \mu \mathrm{g}$ of total membrane protein was incubated with different concentrations (0.06-14 $\mathrm{nM})$ of the A2AR antagonist $3[\mathrm{H}] \mathrm{ZM} 241385$ in $500 \mu \mathrm{l}$ binding buffer (20 mM HEPES $\mathrm{pH} 7.4,100 \mathrm{mM} \mathrm{NaCl})$. Adenosine deaminase (0.1 U) was added to degrade the adenosine released from the membranes and the membranes were incubated at $22^{\circ} \mathrm{C}$ for 1 h. Non-specific binding was determined in the presence of $10 \mathrm{mM}$ theophylline. Measurements were performed in duplicate. After incubation, bound and free ligand were separated on Whatmann GF/B filters pretreated with $0.1 \%$ polyethylenimine using a Brandel cell harvester. The filters were washed three times with binding buffer and the amount of bound radioligand was measured on a liquid scintillation counter. The $\mathrm{Kd}$ and Bmax are determined by curve fitting using KaleidaGraph software (Synergy Software).

\section{Endo $\mathrm{H}$ treatment}

mIL-10 protein was deglycosylated by treatment with $5 \mathrm{U}$ endo H (New England Biolabs) according to the manufacturer's instructions. Supernatant samples (approximately $2.8 \times 10^{7}$ cells) from a methanol induced culture were combined with $5 \mathrm{U}$ endo $\mathrm{H}$ and incubated overnight followed by precipitation with DOC/TCA and separation on a $15 \%$ SDS-PAGE gel.

\section{Electron microscopy}

Samples were prepared for EM according to Baharaeen et al. [32]. Yeast cells were fixed for $2 \mathrm{~h}$ on ice in $1.5 \%$ paraformaldehyde and 3\% glutaraldehyde in $0.05 \mathrm{M}$ sodium cacodylate buffer, $\mathrm{pH}$ 7.2. After washing three times for $20 \mathrm{~min}$ in buffer, cells were treated with a $6 \%$ aqueous solution of potassium permanganate for $1 \mathrm{~h}$ at room temperature. After washing three times for $20 \mathrm{~min}$ in buffer, cells were dehydrated through a graded ethanol series, including bulk staining with $2 \%$ uranyl acetate at the $50 \%$ ethanol step, followed by embedding in Spurr's resin. Ultrathin sections of a gold interference color were cut using an ultra microtome (Ultracut E; Reichert-Jung), post-stained with uranyl acetate and lead citrate in a Leica ultrastainer, and then collected on formvar-coated copper slot grids. They were viewed with a transmission electron microscope 1010 (JEOL, Tokyo, Japan). 


\section{Mass spectrometric analysis}

For peptide mapping, $1 \mathrm{ml}$ of culture supernatants $(\sim 9 \times$ $10^{8}$ cells) were precipitated with DOC/TCA, separated on SDS-PAGE, and stained with colloidal Coomassie Brilliant Blue.

The bands were cut out of the gel and washed with 100 $\mu \mathrm{l}$ of water, then with $100 \mu \mathrm{l}$ of $50 \%$ acetonitrile in water, and then with $100 \mu \mathrm{l}$ of $100 \%$ acetonitrile. The gel slices were dried in a SpeedVac centrifuge. Trypsin (50 ng) was added in a volume of $50 \mathrm{mM} \mathrm{NH}_{4} \mathrm{HCO}_{3}$ buffer ( $\mathrm{pH} \mathrm{8.0)}$ that covered the slices, and the tubes were incubated overnight at $37^{\circ} \mathrm{C}$. Then, $50 \mu \mathrm{l}$ of acetonitrile was added, and the tubes were shaken well for $10 \mathrm{~min}$. The supernatant was collected in a $500 \mu \mathrm{l}$ tube, and the gel pieces were incubated a further $10 \mathrm{~min}$ in $30 \mu \mathrm{l}$ of water; $50 \mu \mathrm{l}$ of acetonitrile was added and the tube was shaken another 10 min. The second supernatant was combined with the first one, and the samples were vacuum evaporated to dryness. The dried material was reconstituted in $10 \mu \mathrm{l}$ of 0.1\% TFA in water and loaded on a C18 ZipTip (Millipore, Bedford, MA, USA) for desalting. Elution was done with $3 \mu \mathrm{l} 50 \%$ AcCN containing 0.1\% TFA. One microliter of the eluate was spotted on a location previously spotted with $1 \mu \mathrm{l}$ of $4 \mathrm{mg} / \mathrm{ml} \mathrm{HCCA}$ in 2:1 acetonitrile: water containing $0.05 \%$ TFA. Positive ion mode reflectron analysis was performed on an ABI4700 MALDI-TOF/TOF analyzer Bruker Reflex IV mass spectrometer tuned and calibrated in the $900-3500 \mathrm{~m} / \mathrm{z}$ range. Peptide masses were searched with MASCOT against known Pichia protein sequences.

\section{FACS analysis}

Precultures $(5 \mathrm{ml})$ from positive clones were grown in YPD for $24 \mathrm{~h}$. $\mathrm{OD}_{600}$ was measured and cultures were diluted to OD 1 in $2 \mathrm{ml} \mathrm{BMGY}$ in a 24-well plate and grown for $24 \mathrm{~h}$, after which they were washed twice with distilled water and induced for $24 \mathrm{~h}$ in BMMY. Surface expression was demonstrated by indirect immunostaining with an antibody against the V5-epitope fused C-terminally to the $\mathrm{V}_{\mathrm{H}} \mathrm{H}$ coding sequence. After induction, $10^{7}$ cells in $1 \mathrm{ml}$ PBS (pH 7.2) supplemented with 0.1\% BSA (PBS/BSA), were incubated with $1 \mu \mathrm{l} / \mathrm{ml}$ anti-V5 antibody $(1 \mu \mathrm{g} / \mu \mathrm{l}$; Invitrogen), washed with $\mathrm{PBS} / \mathrm{BSA}$, and incubated with $1 \mu \mathrm{l} / \mathrm{ml}$ Alexa fluor 488-labeled goat antimouse IgG $(1 \mu \mathrm{g} / \mu \mathrm{l}$; Molecular Probes). After washing twice with PBS/BSA, the cells were analyzed on a BD FACS Calibur cytometer.

\section{Competing interests}

The authors declare that they have no competing interests.

\section{Authors' contributions}

MG identified the HACl intron, performed the studies on HAC1(S) overexpression, evaluated the effect of HAC1(S) overexpression on $\mathrm{mlL}-10$ and on membrane proteins and drafted the manuscript. SR performed the surface display experiments. PJ assisted in the mIL10 experiments. PA completed the trans-sial- idase assay. KVC helped in setting up the radioligand binding assays and reviewing the manuscript. RD prepared the EM pictures. NC reviewed the final manuscript. All authors read and approved the final manuscript.

\section{Acknowledgements}

MG holds a fellowship of the Institute for the Advancement of Scientific and Technological Research in Industry (IWT). KVC holds a postdoctoral fellowship of the Fund for Scientific Research Flanders (FWO). We would like to thank Professor Yuru Deng for the identification of the cubic membrane morphology in the TEM pictures and Paco Hulpiau for the multiple sequence alignment.

\section{Author Details}

1Department of Biochemistry and Microbiology, Ghent University, Ghent, Belgium, 2Department for Molecular Biomedical Research, VIB, Zwijnaarde, Belgium, ${ }^{3}$ Department of Biomedical Molecular Biology, Ghent University, Ghent, Belgium, ${ }^{4}$ Department of Dermatology, Brigham and Women's Hospital, Harvard Medical School, Boston, MA, USA, 5Oxyrane Belgium, Zwijnaarde, Belgium and ${ }^{\circ}$ Department of Physiology, Ghent University, Ghent, Belgium

Received: 1 March 2010 Accepted: 30 June 2010

Published: 30 June 2010

\section{References}

1. Cox JS, Walter P: A novel mechanism for regulating activity of a transcription factor that controls the unfolded protein response. Cell 1996, 87(3):391-404

2. Travers KJ, Patil CK, Wodicka L, Lockhart DJ, Weissman JS, Walter P: Functional and genomic analyses reveal an essential coordination between the unfolded protein response and ER-associated degradation. Cell 2000, 101(3):249-258.

3. Zhou J, Liu CY, Back SH, Clark RL, Peisach D, Xu Z, Kaufman RJ: The crystal structure of human IRE1 luminal domain reveals a conserved dimerization interface required for activation of the unfolded protein response. Proc Natl Acad Sci USA 2006, 103(39):14343-14348.

4. Kimata $Y$, Ishiwata-Kimata $Y$, Ito T, Hirata A, Suzuki T, Oikawa D, Takeuchi $M$, Kohno K: Two regulatory steps of ER-stress sensor Ire1 involving its cluster formation and interaction with unfolded proteins. J Cell Biol 2007, 179(1):75-86.

5. Ruegsegger $\mathrm{U}$, Leber $\mathrm{JH}$, Walter P: Block of HAC1 mRNA translation by long-range base pairing is released by cytoplasmic splicing upon induction of the unfolded protein response. Cell 2001, 107(1):103-114.

6. Yoshida H, Matsui T, Yamamoto A, Okada T, Mori K: XBP1 mRNA is induced by ATF6 and spliced by IRE1 in response to ER stress to produce a highly active transcription factor. Cell 2001, 107(7):881-891.

7. Shen X, Ellis RE, Lee K, Liu CY, Yang K, Solomon A, Yoshida H, Morimoto R, Kurnit DM, Mori K, et al.: Complementary signaling pathways regulate the unfolded protein response and are required for $C$. elegans development. Cell 2001, 107(7):893-903.

8. Saloheimo M, Valkonen M, Penttila M: Activation mechanisms of the HAC1-mediated unfolded protein response in filamentous fungi. $\mathrm{Mol}$ Microbiol 2003, 47(4):1149-1161.

9. Gasser B, Maurer M, Gach J, Kunert R, Mattanovich D: Engineering of Pichia pastoris for improved production of antibody fragments. Biotechnol Bioeng 2006, 94(2):353-361.

10. Resina $D$, Bollok $M$, Khatri NK, Valero F, Neubauer $P$, Ferrer $P$. Transcriptional response of $P$. pastoris in fed-batch cultivations to Rhizopus oryzae lipase production reveals UPR induction. Microb Cell Fact 2007, 6:21.

11. Aragon T, van Anken E, Pincus D, Serafimova IM, Korennykh AV, Rubio CA, Walter $P$ : Messenger RNA targeting to endoplasmic reticulum stress signalling sites. Nature 2009, 457(7230):736-740

12. Kohno K: Stress-sensing mechanisms in the unfolded protein response: similarities and differences between yeast and mammals. J Biochem 147(1):27-33.

13. Mori K: Frame switch splicing and regulated intramembrane proteolysis: key words to understand the unfolded protein response. Traffic 2003, 4(8):519-528.

14. Graf A, Gasser B, Dragosits M, Sauer M, Leparc GG, Tuchler T, Kreil DP, Mattanovich D: Novel insights into the unfolded protein response using Pichia pastoris specific DNA microarrays. BMC Genomics 2008, 9:390. 
15. Ogawa N, Mori K: Autoregulation of the $\mathrm{HAC1}$ gene is required for sustained activation of the yeast unfolded protein response. Genes Cells 2004, 9(2):95-104.

16. Belden WJ, Barlowe C: Deletion of yeast p24 genes activates the unfolded protein response. Mol Biol Cell 2001, 12(4):957-969.

17. Liu YY, Woo JH, Neville DM Jr: Overexpression of an anti-CD3 immunotoxin increases expression and secretion of molecular chaperone BiP/Kar2p by Pichia pastoris. Appl Environ Microbio/ 2005, 71(9):5332-5340.

18. Cox JS, Shamu CE, Walter P: Transcriptional induction of genes encoding endoplasmic reticulum resident proteins requires a transmembrane protein kinase. Cell 1993, 73(6):1197-1206.

19. Kawahara T, Yanagi H, Yura T, Mori K: Endoplasmic reticulum stressinduced mRNA splicing permits synthesis of transcription factor $\mathrm{Hac} 1 \mathrm{p} / \mathrm{Ern} 4 \mathrm{p}$ that activates the unfolded protein response. Mol Bio/ Cell 1997, 8(10):1845-1862.

20. Menzel R, Vogel F, Kargel E, Schunck WH: Inducible membranes in yeast: relation to the unfolded-protein-response pathway. Yeast 1997, 13(13):1211-1229.

21. Cox JS, Chapman RE, Walter $P$ : The unfolded protein response coordinates the production of endoplasmic reticulum protein and endoplasmic reticulum membrane. Mol Biol Cell 1997, 8(9):1805-1814.

22. Sriburi R, Jackowski S, Mori K, Brewer JW: XBP1: a link between the unfolded protein response, lipid biosynthesis, and biogenesis of the endoplasmic reticulum. J Cell Biol 2004, 167(1):35-41.

23. Schuck S, Prinz WA, Thorn KS, Voss C, Walter P: Membrane expansion alleviates endoplasmic reticulum stress independently of the unfolded protein response. J Cell Bio/ 2009, 187(4):525-536.

24. Valkonen M, Penttila M, Saloheimo M: Effects of inactivation and constitutive expression of the unfolded-protein response pathway on protein production in the yeast Saccharomyces cerevisiae. Appl Environ Microbiol 2003, 69(4):2065-2072.

25. Breinig F, Diehl B, Rau S, Zimmer C, Schwab H, Schmitt MJ: Cell surface expression of bacterial esterase A by Saccharomyces cerevisiae and its enhancement by constitutive activation of the cellular unfolded protein response. Appl Environ Microbiol 2006, 72(11):7140-7147.

26. Jacobs PP, Ryckaert S, Geysens S, De Vusser K, Callewaert N, Contreras R: Pichia surface display: display of proteins on the surface of glycoengineered Pichia pastoris strains. Biotechnol Lett 2008, 30(12):2173-2181

27. Boder ET, Wittrup KD: Yeast surface display for screening combinatorial polypeptide libraries. Nat Biotechnol 1997, 15(6):553-557.

28. Shusta EV, Holler PD, Kieke MC, Kranz DM, Wittrup KD: Directed evolution of a stable scaffold for T-cell receptor engineering. Nat Biotechnol 2000, 18(7):754-759.

29. Zhang R, Kim TK, Qiao ZH, Cai J, Pierce WM Jr, Song ZH: Biochemical and mass spectrometric characterization of the human CB2 cannabinoid receptor expressed in Pichia pastoris--importance of correct processing of the N-terminus. Protein Expr Purif 2007, 55(2):225-235.

30. Vervecken W, Kaigorodov V, Callewaert N, Geysens S, De Vusser K, Contreras R: In vivo synthesis of mammalian-like, hybrid-type N-glycans in Pichia pastoris. Appl Environ Microbiol 2004, 70(5):2639-2646.

31. Weiss HM, Grisshammer R: Purification and characterization of the human adenosine $\mathrm{A}(2 \mathrm{a})$ receptor functionally expressed in Escherichia coli. Eur J Biochem 2002, 269(1):82-92.

32. Baharaeen S, Vishniac HS: A fixation method for visualization of yeast ultrastructure in the electron microscope. Mycopathologia 1982, 77(1):19-22.

doi: 10.1186/1475-2859-9-49

Cite this article as: Guerfal et al., The HAC1 gene from Pichia pastoris: characterization and effect of its overexpression on the production of secreted, surface displayed and membrane proteins Microbial Cell Factories 2010, 9:49

\section{Submit your next manuscript to BioMed Central} and take full advantage of:

- Convenient online submission

- Thorough peer review

- No space constraints or color figure charges

- Immediate publication on acceptance

- Inclusion in PubMed, CAS, Scopus and Google Scholar

- Research which is freely available for redistribution

Submit your manuscript at www.biomedcentral.com/submit
C BioMed Central 